\title{
Histopathological Features of the Terminal Ileum in Lymphocytic and Collagenous Colitis: A Study of 32 Cases and Review of Literature
}

\author{
Vijayalakshmi Padmanabhan, M.D., Peter W. Callas, Ph.D., Shuan C. Li, M.D., Thomas D. Trainer, M.D. \\ Departments of Pathology (VP, SCL, TDT) and Biostatistics (PWC), University of Vermont College of \\ Medicine, Burlington, Vermont
}

Biopsy specimens from the terminal ileum of 32 patients with the histopathological diagnosis of lymphocytic colitis or collagenous colitis and 11 control individuals were evaluated for the presence or absence of ileal mucosal abnormalities and for the number of intraepithelial lymphocytes, assessed by immunohistochemical stains for the pan T-cell marker, CD3. We found that the mean CD3 counts in patients with lymphocytic/collagenous colitis were significantly higher than those in the control group. Seven of 14 patients with collagenous colitis and 14 of 18 patients with lymphocytic colitis revealed an increase in intraepithelial $T$ lymphocytes when compared with the control group $(P=.001)$. Other notable changes included ileal villous atrophy in one case of lymphocytic colitis and in three cases of collagenous colitis and epithelial damage with thickened subepithelial collagen in two cases of collagenous colitis.

KEY WORDS: Collagenous colitis, Ileal villous atrophy, Lymphocytic colitis, Terminal ileum.

Mod Pathol 2003;16(2):115-119

Lymphocytic colitis (1-4) and collagenous colitis (1, 3-7) consist of a spectrum of related clinicopathological entities. Collagenous colitis primarily affects middle-aged and older women, who present with prolonged watery diarrhea. Patients with lymphocytic colitis also present with prolonged watery diarrhea, but unlike those with collagenous colitis, the condition affects both genders of all ages. Pa-

Copyright () 2003 by The United States and Canadian Academy of Pathology, Inc.

VOL. 16, NO. 2, P. 115, 2003 Printed in the U.S.A.

Date of acceptance: November 8, 2002.

The abstract was presented as a poster at the United States and Canadian Academy of Pathologists meeting in New Orleans, Louisiana, in March 2000 .

Address reprint requests to: Thomas D. Trainer, M.D., Department of Pathology, Fletcher Allen Health Care, 111 Colchester Avenue, Burlington, VT 05401; e-mail: thomas.trainer@vtmednet.org.

DOI: 10.1097/01.MP.0000051990.80904.AF tients with lymphocytic and collagenous colitis are usually normal by colonoscopic examination. Because the diagnosis requires microscopic evaluation of the colonic mucosa, the term microscopic colitis has also been used by some $(2,8)$. In both conditions there is an increase in lymphocytes within the epithelium of the surface and within the crypts (2). This characteristic feature is frequently accompanied by surface epithelial degeneration and increased chronic inflammation in the lamina propria. Evidence of chronic mucosal injury, such as crypt distortion and architectural disarray, is generally lacking (9). However, subepithelial collagen thickening is seen only in collagenous colitis ( 1 , 3-7).

In normal subjects, $80-90 \%$ of colonic and ileal intraepithelial lymphocytes are T cells $(9,10)$, and $5-40 \%$ of these are of the $\gamma \delta$ subtype (11). Mosnier et al. (12) showed that the colonic intraepithelial lymphocytes in lymphocytic and collagenous colitis are CD3+/CD8 + T cells. The terminal ileum can be affected by many inflammatory conditions that primarily involve the colon. Identification of ileal inflammation may be significant in distinguishing certain inflammatory conditions such as ulcerative colitis and Crohn disease. Prior studies of lymphocytic and collagenous colitis have identified abnormal findings in the duodenum $(13,14)$ and jejunum (15-19), but only a few studies have described the changes in the mucosa of the terminal ileum $(1,7$, 12, 20-24). In these studies, the terminal ileum has been shown to have normal morphological features $(1,12)$ or to demonstrate variable degrees of villous atrophy $(7,21,23,24)$ with or without thickening of the subepithelial collagen table (20, 22; Table: 1). Specific quantitative references to the intraepithelial lymphocyte population are limited (12).

We report on the ileal mucosal findings of 18 patients with lymphocytic colitis and 14 patients with collagenous colitis and compare them with a control group of 11 subjects. 
TABLE 1. Studies of Lymphocytic/Collagenous/Microscopic Colitis Including the Terminal Ileum

\begin{tabular}{|c|c|c|c|}
\hline Reference & Year & Colon Histology (Number of Cases) & Ileum Histology (Number of Cases) \\
\hline Kingham et al. (1) & 1982 & Microscopic colitis (6) & Normal $(3 / 6)$ \\
\hline Lewis et al. (20) & 1991 & Collagenous colitis (1) & Increase in subepithelial collagen table (1) \\
\hline Larvol et al. (21) & 1991 & Lymphocytic colitis (1) & Ileal villous atrophy (1) \\
\hline Meier et al. (22) & 1991 & Collagenous colitis (1) & Increase in subepithelial collagen (1) \\
\hline Einarsson et al. (23) & 1992 & Lymphocytic colitis (1) & Ileal villous atrophy (1) \\
\hline Veress et al. (7) & 1995 & $\begin{array}{l}\text { Lymphocytic colitis (1); } \\
\text { lymphocytic colitis + collagenous colitis (1) }\end{array}$ & Primary villous atrophy (2) \\
\hline Mosnier et al. (12) & 1996 & Lymphocytic colitis (1); collagenous colitis (4) & Normal (5) \\
\hline Marteau et al. (24) & 1997 & Microscopic colitis (3) & Primary ileal villous atrophy (3) \\
\hline
\end{tabular}

\section{MATERIALS AND METHODS}

Via a computer-assisted search of the surgical pathology files at Fletcher Allen Health Care we identified 18 patients with biopsy-proven lymphocytic colitis and 14 patients with biopsy-proven collagenous colitis in whom ileal biopsies were also included in the initial workup. Eleven adult patients with histologically normal biopsies from the terminal ileum and colon were chosen as controls. Most of the control population was being investigated for a history of diarrhea. Patients with a diagnosis of inflammatory bowel disease or colon cancer and pediatric patients were excluded from the control population.

All biopsies were received in Hollande fixative and embedded in paraffin blocks. The original diagnosis was confirmed by reviewing the hematoxylin-eosin stained slides. From each of the terminal ileum blocks, a section was stained with CD3, a pan T-cell marker (polyclonal, DAKO), using the avidin-biotin detection method. Masson trichrome stain was performed on selected cases to highlight the subepithelial collagen table.

The slides were reviewed individually by three pathologists (VP, TDT, and SCL). Two of the pathologists (TT, SCL) were blinded to the original diagnosis.

\section{Light Microscopy}

The terminal ileum was evaluated for the number of lymphocytes per 100 enterocytes, employing the CD3 immunostain and counting a total of 500 enterocytes. Counts were performed from areas away from mucosa containing lymphoid aggregates. The terminal ileum biopsies were also assessed morphologically on the hematoxylin and eosin-stained sections for architectural distortion and presence of apoptosis in the form of nuclear remnants.

Duodenal biopsies were available for review in eight patients (four with lymphocytic colitis and four with collagenous colitis).

\section{Statistical Analysis}

A mean lymphocyte count per 100 enterocytes was computed for each patient. Mean counts for the three groups were compared via analysis of variance, using Tukey's test to adjust for multiple pairwise comparisons. Intraepithelial lymphocytosis was defined as more than or equal to twice the standard deviation of the mean intraepithelial lymphocyte count/100 enterocytes of the control population. The Fisher exact test was used to compare the intraepithelial lymphocytosis.

\section{RESULTS}

The mean age of patients with lymphocytic colitis was 59 years (range, 32-59 y), whereas that of patients with collagenous colitis was 63 years (range, 35-84 y), compared with the control group, whose main age was 44 years (range, 32-59 y). The interobserver agreement of the lymphocyte count among the three investigators was excellent (reliability coefficient $=0.79$ ) .

In the control group, there were four males and seven females. The mean intraepithelial lymphocyte count per 100 enterocytes was 8.2 (range, 4.714.7; Table 2). The mucosa of one patient in the control group revealed intraepithelial lymphocytosis, with 14.7 lymphocytes per 100 enterocytes but without associated features of epithelial injury. Corresponding colonic biopsies in this patient failed to reveal any evidence of colitis. This patient was being treated for psoriasis. The remaining 10 ileal biopsies were normal. Duodenal biopsies were not available for study in the control group.

There were 4 males and 14 females in the lymphocytic colitis group. The mean intraepithelial lymphocyte count/100 enterocytes was 22.3 (range: 9.3-45.7; Figs. 1, A-B). Of the 14 cases with intraepithelial lymphocytosis, 1 case demonstrated villous atrophy and degeneration of the surface epithelium (Fig. 2). Another showed mild damage to the surface epithelium but without villous blunting. The remaining 16 cases showed normal surface epithelium and normal villous architecture (Table 2).

All 14 patients with collagenous colitis were females. The mean intraepithelial lymphocyte count per 100 enterocytes was 16.7 (range, 8.3-29.7; Table 2). The ileum in 7 patients revealed intraepithelial lymphocytosis. The surface epithelium was normal 


\begin{tabular}{|c|c|c|c|}
\hline Number of Patients & Lymphocytic Colitis (18) & Collagenous Colitis (14) & Control Terminal Ileum (11) \\
\hline $\begin{array}{l}\text { Mean lymphocyte count/100 } \\
\text { epithelial cells }(+/-\mathrm{SD})\end{array}$ & $22.3(+/-10.2)$ & $16.7(+/-6.1)$ & $8.2(+/-2.9)$ \\
\hline $\begin{array}{c}\text { Intraepithelial lymphocyte }> \\
2 \mathrm{SD} \text { of mean of control }\end{array}$ & $14(78 \%)$ & $7(50 \%)$ & $1(9 \%)$ \\
\hline Villous atrophy & 1 & 3 & 0 \\
\hline $\begin{array}{l}\text { Epithelial damage with loss } \\
\text { of mucin }\end{array}$ & 2 & 3 & 0 \\
\hline $\begin{array}{l}\text { Mild increase in subepithelial } \\
\text { collagen }\end{array}$ & 1 & 2 & 0 \\
\hline
\end{tabular}

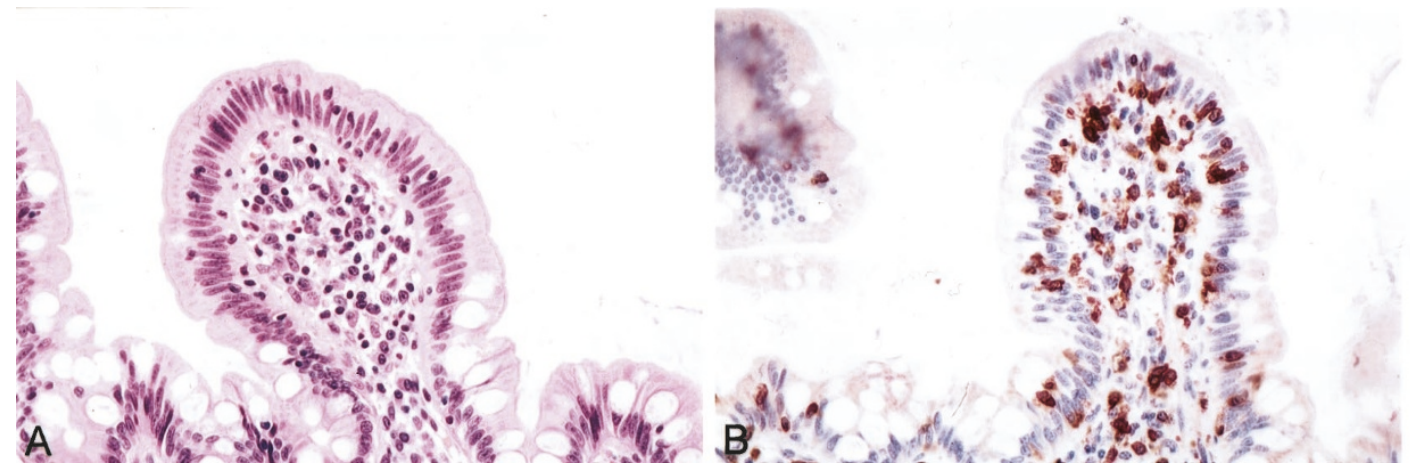

FIGURE 1. Terminal ileum showing intraepithelial lymphocytes in a patient with lymphocytic colitis. A, hematoxylin and eosin stain. B, immunohistochemical stain for T cells, CD3 (DAKO).

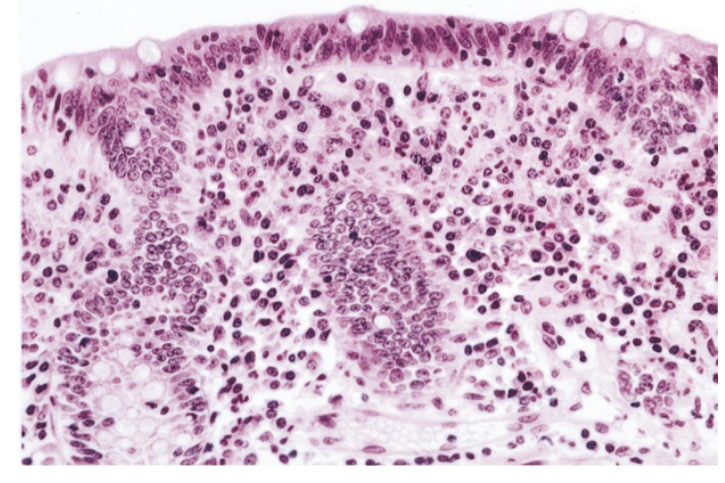

FIGURE 2. Terminal ileum with villous atrophy and increase in intraepithelial lymphocytes in a patient with lymphocytic colitis.

in 11 patients. Surface epithelial damage and villous atrophy were seen in 3 patients. Of the 2 cases with villous atrophy, 1 showed a thickened subepithelial collagen table (Fig. 3).

None of the ileal biopsies in the three groups revealed morphological evidence of increased apoptosis in the form of nuclear remnants. Blood and lymphatic vessels appeared normal in all three groups.

The mean CD3 counts for the lymphocytic colitis (22.3) and collagenous colitis (16.7) groups were significantly higher than those in the control group (8.2; $P<.05)$. The mean CD3 count was marginally higher in the LC group (22.3) than in the CC group (16.7), but this difference was not statistically significant. Intraepithelial lymphocytosis was more common in the LC and CC patients than in the controls (present in $78 \%, 50 \%$, and $9 \%$ of patients, respectively, $P=.001$ )

Duodenal biopsies from eight patients with lymphocytic colitis/collagenous colitis were reviewed (Table: 3). Three patients had a diagnosis of celiac sprue, and mucosal changes typical of sprue were present in these three patients (two patients with lymphocytic colitis and one patient with collagenous colitis). Chronic nonspecific duodenitis was noted in one patient with lymphocytic colitis, and one patient with collagenous colitis showed increased thickness of the subepithelial collagen table of the duodenum. Duodenal biopsies were normal in one patient with lymphocytic colitis and in two patients with collagenous colitis.

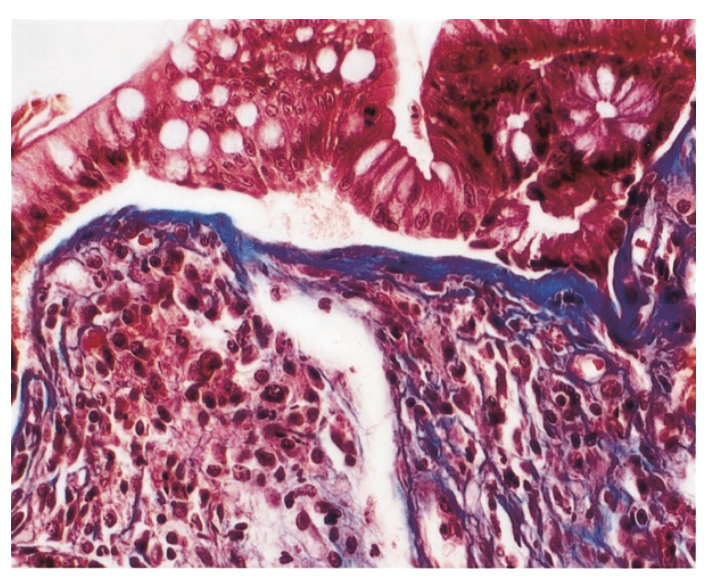

FIGURE 3. Terminal ileum with increase in subepithelial collagen table in a patient with collagenous colitis. Masson trichrome stain. 
TABLE 3. Morphological and Immunohistochemical Features of the Duodenum with Corresponding Intraepithelial Lymphocyte Counts in the Terminal Ileum in Patients with Lymphocytic/Collagenous Colitis

\begin{tabular}{lcc}
\hline \multicolumn{1}{c}{ Morphological Features in Duodenum } & $\begin{array}{c}\text { Lymphocytic Colitis (4 Cases)/\% } \\
\text { Ileal Intraepithelial Lymphocyte } \\
\text { Ileal Intraepithelial Lymphocytes }\end{array}$ & $1 / 15.6$ \\
\hline No pathological features & $2 / 34.6,18.6$ \\
Villous atrophy with increased duodenal intraepithelial lymphocytes & $1 / 25.68$ \\
Chronic nonspecific duodenitis & 0 \\
Increase in subepithelial collagen & $1 / 22.3$ \\
\hline
\end{tabular}

\section{DISCUSSION}

There are relatively few studies describing the changes in the terminal ileum in patients with lymphocytic and collagenous colitis (7, 12, 20-24). However, intraepithelial lymphocytosis in the terminal ileum has not yet been described in these patients. Lewis et al. (20) in 1991 first reported on the involvement of the terminal ileum in a patient with collagenous colitis. Damage to the surface epithelium with broadening of the villi was noted along with a thickened subepithelial collagen table. Larvol et al. (21), described a patient with lymphocytic colitis and ileal villous atrophy. In 1991, Meier et al. (22) recorded the association of collagenous duodenitis and collagenous ileitis in a patient with collagenous colitis. One of our patients showed similar findings. Kingham et al. (1), in their original description of microscopic colitis, reported normal mucosa in the terminal ileum of three patients.

In normal subjects, $80-90 \%$ of colonic intraepithelial lymphocytes are of the CD3+, CD8+ T-cell phenotype (12). In an immunohistochemical study of lymphocytic and collagenous colitis by Mosnier et al. (12), the terminal ileum was biopsied in four of eight patients with collagenous colitis, in one of four patients with lymphocytic colitis, and in five controls without colitis. The intraepithelial lymphocytes in lymphocytic and collagenous colitis were CD3 + CD8 + cytotoxic/suppressor $\mathrm{T}$ cells bearing the $\alpha \beta$ T-cell receptor. The number of ileal intraepithelial lymphocytes was reported to be identical to that of the control population.

In the present series, lymphocytic and collagenous colitis were associated with significant increase in ileal intraepithelial lymphocytes compared with the case of control group. These lymphocytes are $\mathrm{T}$ cells, as shown by immunohistochemical staining with CD3. Intraepithelial lymphocytosis was identified in $78 \%$ of patients with lymphocytic colitis and in $50 \%$ of patients with collagenous colitis. As suggested by Lewis et al. (20), this process may represent a continuation of the disease into the terminal ileum from the colon, similar to the "backwash ileitis" phenomenon seen in ulcerative colitis. However, the changes in the duodenum in some of the patients would not be explained by this theory alone.

A close association between lymphocytic and collagenous colitis and celiac sprue has been seen in some patients (25-30). It is now recognized that the intraepithelial lymphocytes may have a role in the putative immunopathology of celiac sprue (31). Patients with celiac disease manifest a striking increase in the proportion of $\gamma \delta$ T cells relative to $\alpha \beta$ $\mathrm{T}$ cells in the intraepithelial region of the small intestinal mucosa $(11,31)$. Robert et al. (30), in a follow up study of 10 patients with refractory celiac sprue, found collagenous sprue to be a distinctive histological marker for refractory disease in 5 of the 10 patients. Of three patients with collagenous sprue who had colonoscopic examinations, two had findings of collagenous colitis, and a third patient had a focally prominent basement membrane that was not considered to be diagnostic of collagenous colitis. Wolber et al. (28) have shown that sprueassociated colonic lymphocytosis and lymphocytic colitis are histologically indistinguishable. Two of our patients with lymphocytic colitis and another with collagenous colitis had documented abnormalities of the duodenum typical of celiac sprue. This suggests that lymphocytic and collagenous colitis may, in fact, be representative of a more generalized disease of the gut, involving both the large and the small intestines. Presumably, the increased numbers of intraepithelial lymphocytes in these organs represent an immunogenic response in individuals sensitized to luminal antigens, analogous to gluten sensitivity of celiac sprue patients. Large studies that include biopsies from multiple sites in the gut and clinical follow-up are warranted.

Seven cases of primary ileal villous atrophy have been described in the literature in association with microscopic/lymphocytic/collagenous colitis $(7,20$, 23, 24). Larvol et al. (21) and Einarsson et al. (23) each described primary ileal villous atrophy in a patient with lymphocytic colitis. Two patients with primary ileal villous atrophy and lymphocytic colitis were described by Veress et al. (7). One patient also showed features of collagenous colitis. Marteau et al. (24) described three cases of primary ileal villous atrophy associated with microscopic colitis and suggested a shared pathogenesis. In the present study, one patient with lymphocytic colitis and three patients with collagenous colitis showed features of ileal villous atrophy. This association needs to be further clarified.

In summary, this immunohistochemical study showed intraepithelial lymphocytosis of the termi- 
nal ileum, with or without epithelial damage, in patients with lymphocytic/collagenous colitis. There may be changes in the duodenum that suggest celiac sprue. Hypersensitivity to intraluminal agents similar to that seen with celiac sprue may represent the fundamental pathogenetic mechanism. [16-18]

Acknowledgments: The authors thank Ms. Janet Mitchell for assistance with immunohistochemistry.

\section{REFERENCES}

1. Kingham JGC, Levison DA, Ball JA, Dawson AM. Microscopic colitis-a cause of chronic watery diarrhea. Br Med J 1982; 285:1601-4.

2. Lazenby AJ, Yardley JH, Giardiello FM, Jessurun J, Bayless TM. Lymphocytic (microscopic) colitis. A comparative histopathological study with particular reference to collagenous colitis. Hum Pathol 1989;20:18-28.

3. Kingham JG. Microscopic colitis. Gut 1991;32:234-5.

4. Jawhari A, Talbot IC. Microscopic, lymphocytic and collagenous colitis. Histopathology 1996;29:101-10.

5. Lindstrom CG. "Collagenous colitis" with watery diarrhea-a new entity? Pathol Eur 1976;11:87-9.

6. Jessurun J, Yardley JH, Giardiello FM, Hamilton SR, Bayless TM. Chronic colitis with thickening of the subepithelial collagen layer (collagenous colitis): histopathological findings in 15 patients. Hum Pathol 1987;18:839-48.

7. Veress B, Lofberg R, Bergman L. Microscopic colitis syndrome. Gut 1995;36:880-6.

8. Read NW, Krejs GJ, Read MG, Santa Ana CA, Morawski SG, Fordtran JS. Chronic diarrhea of unknown origin. Gastroenterology 1980;78:264-71.

9. Goldstein NS, Gyorfi T. Focal lymphocytic and collagenous colitis. Patterns of Crohn's colitis? Am J Surg Pathol 1999;23: 1075-81.

10. Hirata I, Berrebi G, Austin LL, Keren DF, Dobbins WO. Immunohistochemical characterization of intraepithelial and lamina propria lymphocytes in control ileum and colon in inflammatory bowel disease. Dig Dis Sci 1986;31:593-603.

11. Kagnoff MF. Current concepts in mucosal immunity III. Ontogeny and function of $\gamma \delta \mathrm{T}$ cells in the intestine. Am J Physiol 1998;274:G455-8.

12. Mosnier J-F, Larvol L, Barge J, DuBois S, De La Bigne G, Henin D, et al. Lymphocytic and collagenous colitis: an immunohistochemical study. Am J Gastroenterol 1996;91: 709-13.

13. Stolte M, Ritter M, Borchard F, Koch-Scherrer G. Collagenous gastroduodenitis on collagenous colitis. Endoscopy 1990;22:186-7.
14. Eckstein RP, Dowsett JF, Riley JW. Collagenous enterocolitis: a case of collagenous colitis with involvement of the small intestine. Am J Gastroenterol 1988;83:767-71.

15. Bossart R, Henry K, Booth CC, Doe WF. Subepithelial collagen in intestinal malabsorption. Gut 1975;16:18-22.

16. Hamilton I, Sanders S, Hopwood D, Bouchier IA. Collagenous colitis associated with small intestinal villous atrophy. Gut 1986;27:1394-8.

17. Armes J, Gee DC, Macrae FA, Schroeder W, Bhathal PS. Collagenous colitis: jejunal and colorectal pathology. J Clin Pathol 1992;45:784-7.

18. McCashland TM, Donovan JP, Strobach RS, Linder J, Quigley EMM. Collagenous enterocolitis: a manifestation of glutensensitive enteropathy. J Clin Gastroenterol 1992;15:45-51.

19. Moayyedi P, O’Mahony S, Jackson P, Lynch DAF, Dixon MF, Axon ATR. Small intestine in lymphocytic and collagenous colitis: mucosal morphology, permeability and secretory immunity to gliadin. J Clin Pathol 1997;50:527-9.

20. Lewis FW, Warren GH, Goff JS. Collagenous colitis with involvement of terminal ileum. Dig Dis Sci 1991;36:1161-3.

21. Larvol L, Brousse N, Barge J, Chagnon JP, Cerf M. Association d'une colte lymphocytaire et d'une atrophie villositaire ileale [abstract]. Gastroenterol Clin Biol 1991;15:A289.

22. Meier PN, Otto P, Ritter M, Stolte M. Kollagene duodenitis und ileitis bei einer Patientin mit Kollagener Kolitis. Leber Magen Darm 1991;21:231-2.

23. Einarsson K, Eusufzai S, Johansson V, Lofbrg R, Theodoresson E, Veress B. Villous atrophy of the distal ileum and lymphocytic colitis in a female with bile duct malabsorption. Eur J Gastroenterol Hepatol 1992;4:585-90.

24. Marteau P, Lavergne-Slove A, Lemann M, Bouhnik Y, Bertheau $\mathrm{P}$, Becheur $\mathrm{H}$, et al. Primary ileal villous atrophy is often associated with microscopic colitis. Gut 1997;41:561-4.

25. Breen EG, Farren C, Connolly CE, McCarthy CF. Collagenous colitis and celiac disease [letter]. Gut 1987;28:364.

26. DuBois RN, Lazenby AJ, Yardley JH, Hendrix TR, Bayless TM, Giardiello FM. Lymphocytic enterocolitis in patients with refractory sprue. JAMA 1989;262:935-7.

27. O'Mahony S, Nawroz IM, Fergusen A. Celiac disease and collagenous colitis. Postgrad Med J 1990;66:238-41.

28. Wolber R, Owen D, Freeman H. Colonic lymphocytosis in patients with celiac sprue. Hum Pathol 1990;21:1092-6.

29. Fine KD, Lee EL, Meyer RL. Colonic histopathology in untreated celiac sprue or refractory sprue: is it lymphocytic colitis or colonic lymphocytosis? Hum Pathol 1998;29:143340.

30. Robert ME, Ament ME, Weinstein WM. The histologic spectrum and clinical outcome of refractory and unclassified sprue. Am J Surg Pathol 2000;24:676-87.

31. Shuppan D. Current concepts in celiac disease pathogenesis. Gastroenterology 2000;119:234-42. 